\title{
On the problems and ways of solving the problem of renewing the agricultural machinery park in the agricultural sector
}

\author{
Igor Pigorev ${ }^{1}$, Danil Zyukin ${ }^{2}$ \\ Kursk State Agricultural Academy, Russia
}

\begin{abstract}
The problem of updating the fleet of agricultural machinery and introducing technologies into agricultural production is acute. In the current foreign policy and economic conditions, the issue of ensuring food security has become extremely important, in connection with which there is an urgent need to increase the efficiency of agricultural production in a short time. In such a situation, the most effective way is to intensify production, and in this process, machinery and equipment play a primary role. The study found that in the Russian Federation in the period 2015-2020. There was a reduction in the fleet of agricultural machinery, which caused an increase in the load on the existing fleet of tractors and combine harvesters. The rates of renewal of agricultural machinery concerning tractors and combine harvesters have decreased, which, together with other conditions, negatively characterizes the situation with the renewal of the fleet of machinery in agricultural production. In the context of ensuring the implementation of the policy of import substitution and ensuring food security, the state should provide greater support to agricultural producers when updating the fleet of equipment, since in the context of the weakening of the ruble, the deterioration of the national economic system, the falling purchasing power of the population and other factors, agricultural producers will not be able to independently master additional the financial burden, and the renewal of the material and technical base, especially when it comes to the supply of imported equipment, is an expensive issue.
\end{abstract}

\section{Introduction}

Agrarian production is the basis for ensuring the food security of the state since the level of self-sufficiency of the population with the main types of food products depends on the efficiency of its functioning.

For many years, the agricultural sector in the Russian Federation remained without a regulatory mechanism and state support adequate to its tasks. Because of this, many problems have become much worse. One of these is the technical backwardness of Russian agricultural production from the advanced countries, which predetermines a lower level of intensification and, therefore, the results of activities.

In the context of the food embargo, which was imposed on countries that supported anti-Russian economic sanctions, the task of ensuring food import substitution has become a priority within the framework of state economic policy. However, an accelerated transition in the implementation of import substitution is impossible without appropriate investment support and the introduction of new technologies in agricultural production. Agricultural production, due to its specificity and sectoral risks, does not belong to investmentattractive industries, which is aggravated by all-Russian problems in the economy, generating an unfavorable investment climate.

In the results of agricultural production, the influence of the material and technical factor is high, the use of which causes high financial costs since the technical base of agricultural enterprises must be regularly updated. Therefore, in the absence of stable investment flows directed to the introduction of new production technologies, the efficiency of agricultural production suffers, the competitiveness of domestic agricultural products decreases, which indirectly affects the food security of the state and the implementation of the objectives of the import substitution policy.

\section{Results and Discussion}

\subsection{Problems of updating the agricultural machinery park}

The key problem of renewing the fleet of agricultural machinery and, in general, the introduction of technologies and innovations is the financial one. The profitability of many areas of agricultural production is low, therefore, both own sources and borrowed costs for this area are in short supply. In combination with the low investment attractiveness of agriculture, this predetermined the degradation of the material and technical base of many agricultural enterprises in the country.

In addition to financial problems in the matter of updating the material and technical base, there are difficulties directly with the availability of the production of high-tech agricultural machinery and equipment, therefore, high-performance and high-tech

\footnotetext{
Corresponding author: author@e-mail.org
} 
agricultural machinery and equipment are often purchased abroad [1]. This predetermines a strong dependence on the volatility of the Russian ruble exchange rate, which has significantly devalued in recent years. On the one hand, this created an advantage for export-oriented industries, but there are very few of them in Russian realities [2]. On the other hand, this fact predetermines a significant increase in the cost of imported products, especially technological ones, which to a large extent concerns the task of updating the material and technical base. As a result, the negative consequences outweigh and for export directions, for example, the grain economy suffers greatly from the outdated and inappropriate production and logistics infrastructure, leading to significant losses of grain during its transportation [3].

Another problem that hinders the renewal of agricultural machinery, equipment, and the introduction of innovative technologies in agricultural production, which is also an extremely important issue in the conditions of the formation of the national innovation system, is the personnel issue. With the decline in the prestige of labor in agriculture, many specialists capable of performing intellectual work and working with hightech machinery and equipment have irrevocably moved to other sectors of the national economy. Therefore, a serious problem now is the operation and repair of machinery and equipment entering the balance of agricultural organizations now.

Nevertheless, the gradual modernization of the technological base in agriculture intensified after the introduction of anti-Russian economic sanctions, which necessitates a study of the level of provision of agricultural organizations of the Russian Federation with agricultural machinery and the process of updating technology in agricultural production against the background of the implementation of the policy of import substitution and the functioning of the national economy in conditions of a structural crisis.

\subsection{The state of the material and technical base in agricultural organizations in Russia}

The peculiarities of the territorial division of labor in the Russian Federation affect the process of updating agricultural machinery in different regions. It is most actively promoted in the regions of the South of the country and the regions of the Central Black Earth Zone, that is, in those territories where agriculture is most effective and promising [4].

But even in regions with favorable natural and climatic conditions, the efficiency of, for example, crop production decreases due to soil impoverishment, which necessitates intensification of production [5]. In turn, the intensification of production implies the use of modern technologies, high-performance equipment, more productive and disease-resistant seed material, and fertilizers, which implies high financial costs. At the same time, in conditions of growing competition and a steady decline in real incomes of the population, it is necessary to restrain the growth of the cost of agricultural products, otherwise, this will entail an increase in the cost of products for the end consumer.

The use of agricultural machinery plays a key role in the intensification of agricultural production. After the food embargo was introduced, the process of renewing the agricultural machinery park and introducing the latest technologies in agricultural production, on the one hand, became even more important, since it was necessary to increase the volume of agricultural production in a short time, and on the other hand, it was complicated by the worsening economic situation in the country. Therefore, it is important to analyze how the indicators of the provision of agricultural organizations with tractors and combines have changed in the period after the introduction of the food embargo in 2015 and the strengthening of the processes for the implementation of the import substitution policy (Table $1)$.

Table 1. Provision of agricultural organizations with tractors and combines in the Russian Federation

\begin{tabular}{|l|r|r|r|}
\hline \multicolumn{1}{|c|}{ Indicator } & \multicolumn{1}{|c|}{2015} & 2020 & Growth, \% \\
\hline $\begin{array}{l}\text { Load of arable land per } \\
\text { tractor, ha }\end{array}$ & 308 & 349 & 13,3 \\
\hline $\begin{array}{l}\text { The sowing (planting) of the } \\
\text { corresponding crops falls on } \\
\text { one harvester, ha: }\end{array}$ & & & \\
\hline - grain harvesting & 422 & 451 & 6,9 \\
\hline - corn harvesting & 2008 & 2974 & 48,1 \\
\hline - potato harvesting & 67 & 66 & $-1,5$ \\
\hline - flax harvesting & 70 & 114 & 62,9 \\
\hline $\begin{array}{l}\text { - beet harvester (without } \\
\text { toppers) }\end{array}$ & 396 & 431 & 8,8 \\
\hline
\end{tabular}

Compared to 2015, in 2020 the load on the tractor fleet increased by $13.3 \%$ [6]. The largest increase in the load fell on flax harvesters, and the load on corn harvesters increased by almost half. The smallest increase in the load fell on grain harvesters and beet harvesters, which is explained by the fact that the cultivation of grain crops and sugar beets has always been the main areas of crop production in most farms in the Russian Federation. The constant need to improve the efficiency of grain production and sugar beet production forced manufacturers to timely resolve the issue of updating the fleet of specialized harvesters. At the same time, the production of these types of products has always been at a sufficient level, and after the introduction of the food embargo, there was no urgent need to increase the area under crops of grain and sugar beets to meet the needs of the population. The decrease in the load is observed only concerning potato harvesters since during this period in the Russian Federation there was a decrease in potato production. The level of supply of the Russian population with potatoes meets the target indicators established for this type of product by the Food Security Doctrine for the period up to 2030, therefore, apparently, there is no need to increase potato production, and the Russian Federation does not yet claim to be an exporter for this type of product. 
It should be noted that the increase in the load on tractors and combine harvesters are also associated with a reduction in the fleet for these types of agricultural machinery (Table 2).

Table 2. Fleet of tractors and combine harvesters in agricultural organizations of the Russian Federation, thousand

\begin{tabular}{|l|r|r|r|}
\hline \multicolumn{1}{|c|}{ Indicator } & \multicolumn{1}{c|}{2015} & \multicolumn{1}{c|}{2020} & Growth, \% \\
\hline Tractors & 233,6 & 203,6 & $-12,8$ \\
\hline Combines: & & & \\
\hline - grain harvesting & 61,4 & 53,9 & $-12,2$ \\
\hline - corn harvesting & 0,8 & 0,6 & $-25,0$ \\
\hline - flax harvesting & 0,4 & 0,2 & $-50,0$ \\
\hline - potato harvesting & 2,3 & 1,9 & $-17,4$ \\
\hline - forage harvesting & 14,0 & 11,4 & $-18,6$ \\
\hline $\begin{array}{l}\text { Beet harvesters (without } \\
\text { toppers) }\end{array}$ & 2,2 & 1,9 & $-13,6$ \\
\hline
\end{tabular}

The fleet of tractors and combine harvesters decreased significantly in 2020. Even in the successfully developing grain farming, the reduction of harvesters was $12.2 \%$, i.e., every eighth unit was discontinued. The same reduction dynamics are recorded among tractors. The largest reduction affected flax harvesters, the load on which increased the most in the dynamics for 20152020. The percentage reduction in combine harvesters and beet harvesters is higher than the increase in the load on them. It should be considered that the productivity of the new equipment is much higher than that of the old, therefore, even with a numerical reduction in the fleet, productivity does not suffer or becomes higher. The reduction in corn harvesters turned out to be lower than the increase in the load on them, but at the same time, there was a reduction in the acreage under the crop, so it should be assumed that most likely the fleet was replenished with high-performance equipment against the background of a decrease in the number of corn harvesters.

There was a decrease in the number of other types of agricultural machinery, for example, involved in sowing and harvesting (Fig. 1).

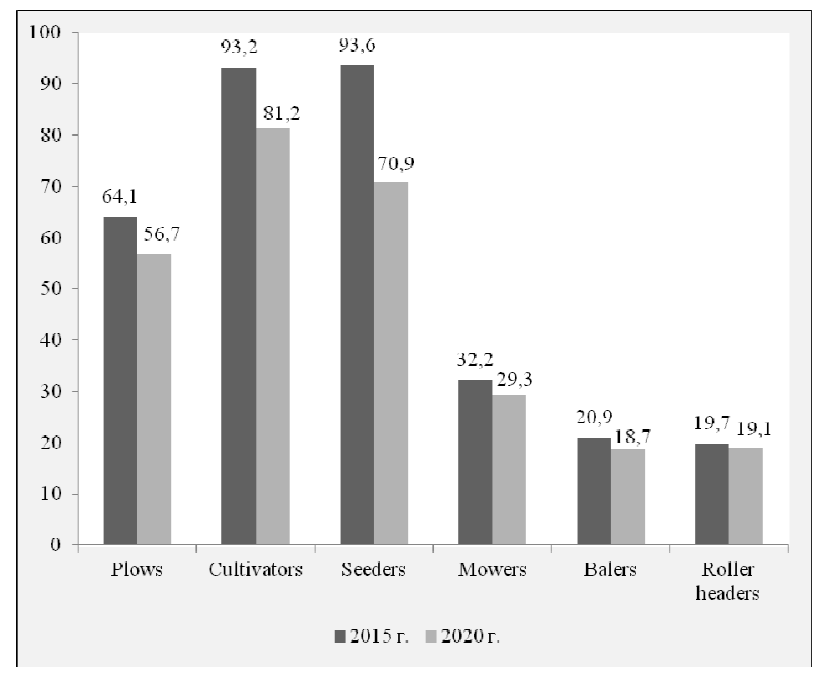

Fig. 1. Agricultural machinery park involved in sowing and harvesting, thousand units
The number of seeders decreased by almost a quarter, more than $10 \%$ was the reduction of cultivators, plows and balers.

At the same time, the fleet of agricultural machinery involved in the care of crops, on the contrary, has been replenished (Fig. 2).

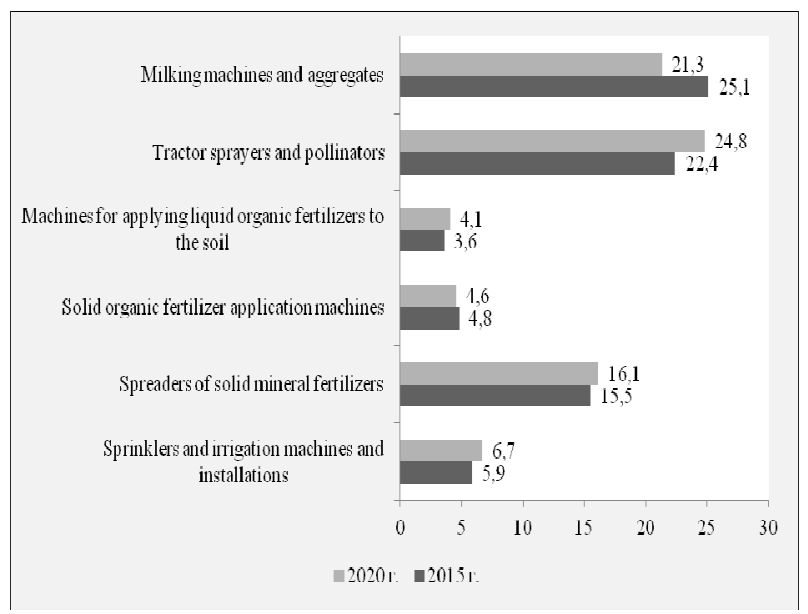

Fig. 2. The fleet of agricultural machinery involved in the care of crops and in animal husbandry, thousand units

More than $13 \%$ was an increase in the number of sprinkler and irrigation machines and installations, as well as machines for applying liquid organic fertilizers to the soil, over $10 \%$ was an increase in the number of tractor sprayers and pollinators. The park of machines for applying solid organic fertilizers has decreased by $4 \%$, and the number of milking installations and units has also decreased.

\subsection{Analysis of the process of updating the fleet of equipment in agricultural production}

An important point is the assessment of changes in the coefficients of renewal of the fleet of agricultural machinery (Fig. 3, Fig. 4) [7].

In 2015, the renewal rate of corn harvesters was the highest among tractors and harvesters. In 2019, it also turned out to be higher than the indicators for other types of equipment.

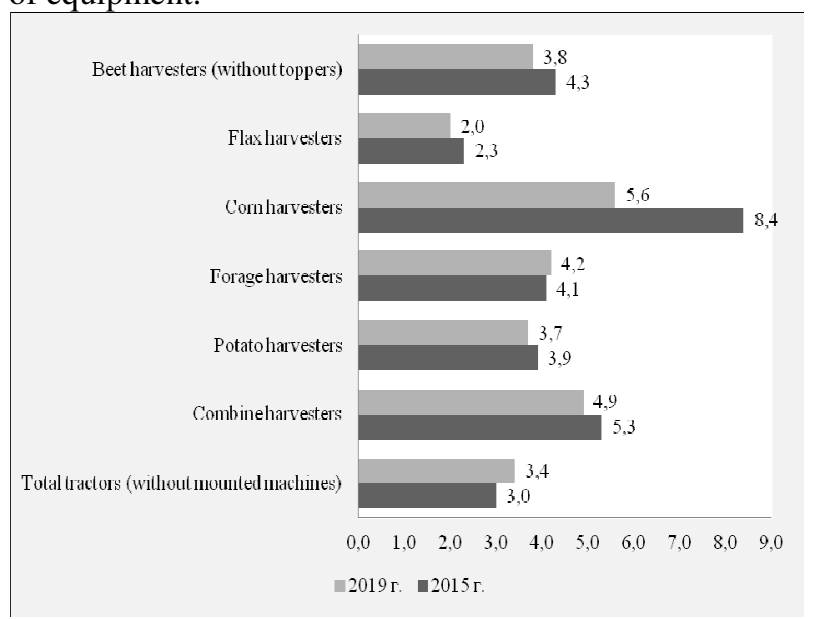

Fig. 3. Renewal rate of tractors and combine harvesters, $\%$ 
Despite the relatively high values of the renewal factor, the fleet of corn harvesters is insufficiently staffed, since even with a reduction in the area under crops, the load on it has increased by half. The tractor fleet, excluding tractors on which any machines are mounted, of all types of equipment in 2019 began to be updated more than in 2015. The coefficients of renewal of the types of equipment that are most common in the Russian Federation (grain and potato harvesters, sugar beet harvesters cars), decreased by $0.3-0.5 \%$. It should be noted that the values of the indicator decreased in the order of decreasing popularity of cultivated crops. The lowest renewal rate is observed concerning flax harvesters, which is quite logical since flax is cultivated mainly in the northern regions and is not as widespread as food crops.

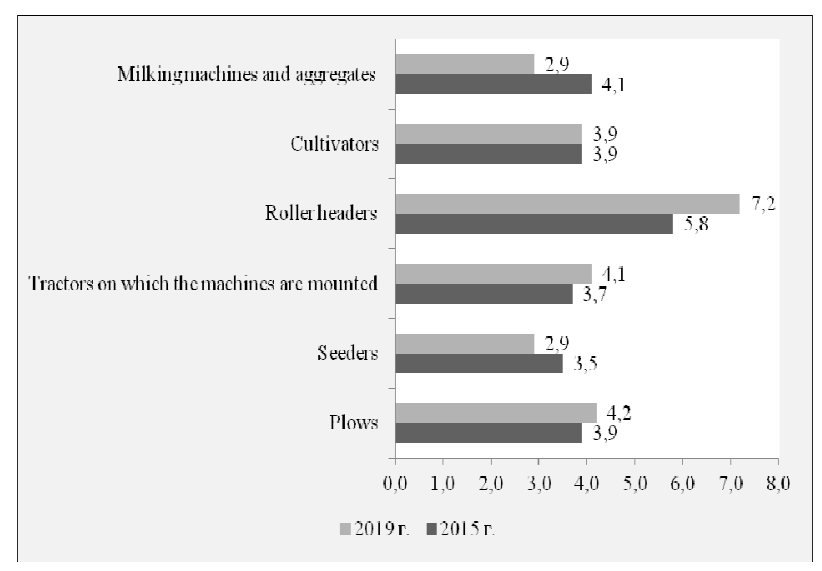

Fig. 4. The coefficient of renewal of certain types of agricultural machinery, $\%$

The renewal rates of small equipment (Fig. 4) decreased only in relation to milking machines and seeders, as noted above, their number also decreased in dynamics.

Thus, the tendencies of changes in the number of agricultural machinery parks are mostly negative, which negatively characterizes the situation with the renewal of the material and technical base of agricultural enterprises.

\section{Conclusion}

The study of the situation with the renewal of the agricultural machinery park in the Russian Federation showed a negative trend. This fact poses a threat given the need, while maintaining the food embargo, to ensure import substitution of food at the expense of domestic producers. The presence of adequate size of the fleet of agricultural machinery in agricultural production is one of the key factors for solving this strategic task.

It should be noted that, both before and after the introduction of counter-sanctions on the part of Russia, not a single comprehensive state program was formed aimed at improving the condition of the agricultural machinery park and increasing the level of its renewal. The existing areas of support and regulation do not provide a comprehensive solution to the current problem.
Subsidizing part of the interest rate, which is essentially the only instrument among state support provided to agrarians in Russia, also has its significant disadvantages.

At this stage, not only remain but also continue to increase the factors and negative trends that impede the intensive renewal of the agricultural machinery park. The key is the unfavorable macroeconomic situation in Russia, expressed by tight monetary policy and high volatility and devaluation of the ruble. Therefore, Russian agrarians, like many other participants in the national economic system, found themselves in a difficult economic situation. Financial difficulties, judging by the results of the study, negatively affected the process of updating agricultural machinery, which significantly increased in value, and the ability to bear the credit burden among agricultural producers decreased.

Consequently, in the matter of updating agricultural machinery and introducing modern technologies into the production process, it is advisable to change the mechanism of state regulation and support. In difficult economic conditions, such measures carry an additional burden on the country's budget, but the feasibility of this is determined by several important facts. First, due to the strategic importance of agricultural production in ensuring national security from the standpoint of ensuring food independence of the state from third countries. Second, due to the instability in the national economy, which undermines the confidence of consumers, producers, and investors, active government participation has traditionally allowed to increase business activity and improve the investment climate. Thirdly, due to the control over the observance of national interests from the standpoint of lean production and the preservation of natural resources and the prevention of situations with barbaric depletion of soils, poisoning of the environment and the aquatic environment with industrial waste.

Thus, it is necessary at the state level to strengthen direct and indirect support of agricultural producers in the following matters: renewal of the agricultural machinery park; providing the industry with qualified personnel capable of carefully and efficiently operating new types of equipment, and carrying out their timely diagnostics and high-quality repairs; overcoming bureaucratic barriers in obtaining state support funds for updating the material and technical base; establishment of preferential tariffs for railway transportation for the transportation of purchased equipment; containment of prices for fuels and lubricants and control over their quality.

\section{References}

1. D. Zyukin, O. Svyatova, R. Soloshenko Economic Annals-XXI, 161 (9-10), 47-50, (2016)

2. G. C. Nina, M. Ukeyima, A. F. Ogori, M. Hlebova, A. P. Glinushkin, A. Laishevtcev, A. Dercanosova, I. Y. Pigorev, S. Plygun, M. Ali 
Shariati Journal of Microbiology, Biotechnology and Food Sciences, 9 (5), 988-993, (2020)

3. D. Zyukin, O. Svyatova, E. Zolotareva, A. Bystritskaya, A. Alyokhina Amazonia Investiga, 9 (25), 461-470, (2020)

4. A. A. Golovin, M. A. Parkhomchuk Development of Agricultural Location Theory. Proceedings of the 30th International Business Information Management Association Conference. Spain Madrid, 1447-1454, (2017)

5. A. Brausmann, L. Bretschger European Economic Review, 108, 1-19, (2018)

6. Federal State Statistics Service Agriculture, hunting and forestry. Retrieved from: https://rosstat.gov.ru/enterprise_economy?print=1

7. EMISS Ratio of equipment renewal Retrieved from: https://www.fedstat.ru/indicator/33751 